\title{
Pan-VEGFR/TIE2 Tyrosine Kinase Inhibitor CEP-11981
}

National Cancer Institute

\section{Source}

National Cancer Institute. Pan-VEGFR/TIE2 Tyrosine Kinase Inhibitor CEP-11981. NCI

Thesaurus. Code C82379.

An orally bioavailable inhibitor of vascular endothelial growth factor receptor (VEGFR) and Tie2 receptor tyrosine kinases with potential antiang iog enic and antineoplastic activities. Pan-VEGFR/T ie2 tyrosine kinase inhibitor CEP-11981 selectively binds to VEGFR and Tie2 receptor tyrosine kinases, which may result in the inhibition of endothelial cell migration, proliferation and survival and the inhibition of tumor cell proliferation and tumor cell death. VEGFR and Tie2 are frequently overexpressed by a variety of tumor cell types and play crucial roles in the regulation of angiogenesis and the maintenance of tumor blood vessels. Tie2 (tyrosine kinase with immunoglobulin-like and EGF-like domains) is activated by angiopoietin-1 (Ang-1). 